\title{
RELEVÂNCIA DO TRABALHO E DA QUALIDADE DE VIDA NO TRABALHO PARA A SOCIEDADE
}

\section{QUALIDADE DE VIDA NO TRABALHO: UM MODELO SISTÊMICO}

Ana Alice Vilas Boas, \& Estelle M. Morin. Qualidade de vida no trabalho: Um modelo sistêmico. Minas Gerais: Editora UFLA, 2021. 196 p.

Compreender os sentidos do trabalho "é um desafio importante para os administradores tendo em vista as múltiplas transformações que têm atingido as organizações e os 'mundos do trabalho'” (Morin, 2001, p. 8).

O tema Qualidade de Vida no Trabalho (QVT) tem despertado ansiedades, indagações e interesses em diferentes esferas da sociedade. As suas aplicação e relevância são verificadas em distintos estudos publicados: relações de gestão e liderança, envolvendo trabalhadores e suas famílias (Rodrigues, Barrichello, \& Morin, 2016); Programas de Assistência ao Empregado (PAE) e concepções de ambientes de trabalho seguros e saudáveis (Calvosa, 2010); difusão de novas tecnologias que afetam o bem-estar psicológico dos colaboradores (Morin, 2011); como docentes e pesquisadores estabelecem maior significado laboral, avaliando as suas produtividade e capacidade de entrega (Vilas Boas \& Morin, 2016; Vilas Boas, Pires, Faria, \& Morin, 2018); composição de modelos de análise de QVT (Vilas Boas \& Morin, 2017, 2021). Esses últimos trabalhos retratam o interesse individual, mas também conjunto, das autoras da obra pelo tema.

Sobre a primeira autora, Ana Alice Vilas Boas é brasileira, administradora, mestre e doutora em Administração (Universidade de Reading), com pós-doutorado pela Ecole des Hautes Etudes Commerciales (HEC-Montreal) (2013). Foi professora da UFRRJ (1993-2008). Desde 2008, é professora titular da UFLA, em Administração. Estelle M. Morin, a segunda autora, é canadense, psicóloga, mestre e doutora em Psicologia (Universidade de Montreal). É pesquisadora e professora titular da HEC, desde 1988.

Em nossa sociedade, o trabalho parece representar um importante valor, exercendo influência sobre a satisfação e a produtividade dos colaboradores (Morin, 2001). A perda do sentido no trabalho e de sua qualidade de realização poderão afetar, mesmo que indiretamente, uma parcela mais significativa da sociedade. Provavelmente, além do que possa ser medido de maneira direta ou consciente. Alguns indicadores, tais como absenteísmo, presenteísmo, queda de produtividade, comportamentos resistentes, desconfianças em relação à empresa e aos gestores, falta de motivação 
e ruptura de contrato psicológico implícito, podem apontar, mesmo silenciosamente, que algo não está em consonância com os objetivos organizacionais (Calvosa, 2010; Rodrigues et al., 2016).

A obra resenhada está dividida em seis capítulos. 0 primeiro versa sobre os sentidos do trabalho e QVT. Nele, as autoras tratam da função psicológica e social do trabalho, origens, definições, modelos e práticas de QVT. Em seguida, é exposto o Modelo Sistêmico de Análise da QVT, assim definido por considerar, de maneira ordenada, os sentidos "do trabalho" e "no trabalho" como forma estruturada para avaliar desde uma "experiência ótima" laboral até o uso de "estratégias defensivas" para a proteção individual e coletiva dos colaboradores (Vilas Boas \& Morin, 2021, p. 35). Esse modelo parte do pressuposto de que QVT varia de indivíduo para indivíduo, de ambiente para ambiente. Por trazer uma pesquisa com docentes de instituições de ensino superior (IES) federais brasileiras, as autoras encerram o capítulo narrando os "sabores e dissabores" do trabalho docente no contexto da Administração Pública.

$\mathrm{Na}$ busca pelo equilíbrio vida-trabalho, para as autoras, os colaboradores organizacionais deverão perceber "valor" (utilidade, serventia, importância, reconhecimento ou dignidade), em propostas de construção social e na cultura vigente, o que possibilitaria tornarem-se agentes ativos no desenvolvimento de prazer, significado e colaboração dos lugares psicológicos ocupados pelo sentido do trabalho, ou mesmo o espaço que esse deveria ocupar como norteador e direcionador de reconhecimento e representações na sociedade contemporânea. Entre diversos colaboradores, especificamente, “a profissão docente possui contornos peculiares". Mostrase diferente das demais atividades laborais devido "à complexidade e ao nível de desgaste físico e emocional que fazem parte da rotina dessa profissão", justificando "a amostra selecionada ser investigada para a análise crítica do modelo apresentado" (Vilas Boas \& Morin, 2021, p. 11).

O segundo capítulo trata dos procedimentos metodológicos usados para coletar os dados e descreve os instrumentos de pesquisa. Para cada tabela utilizada, há destaque, identificação e análise dos indicadores e dos fatores de QVT. Na sequência, são divulgadas a população e a amostra da pesquisa, depois, detalhados os procedimentos de análise dos dados.

O capítulo seguinte descreve os perfis pessoal e profissional docentes. Essas informações são importantes para representar as características do trabalho e as diferenças individuais, essenciais para entender a QVT no contexto do Modelo Sistêmico. No cenário atual, o trabalho docente tem passado por um processo de precarização balizado pelo Produtivismo, pelo excesso de atividades administrativas desempenhadas e pelas condições precárias de trabalho em muitas IES brasileiras, um debate oportuno que o livro traz.

O quarto capítulo trata dos indicadores de QVT dos docentes brasileiros e suas correlações. Por exemplo, o livro mostra uma correlação moderada-positiva entre os indicadores “Equilíbrio Vida-trabalho" e "Bem-estar Psicológico"; ou seja: se o primeiro indicador aumenta, o outro aumenta; se um deles diminui, o outro também diminui. Será interessante para o leitor acompanhar as análises de tais correlações, como a gerada entre os indicadores "Equilíbrio Vida-trabalho" e "Estresse Relacionado ao Trabalho", que possuem correlação inversa. Outro ponto digno de destaque nesse trecho é a análise sobre a possibilidade de diferenças de percepção de docentes dos gêneros masculino e feminino sobre os indicadores de QVT.

O quinto capítulo explicita os fatores de QVT dos docentes brasileiros e suas correlações, mostrando como um aumento ou diminuição na percepção de um fator afeta os demais. Foi observado, por exemplo, que existem correlações fortepositivas entre "Reconhecimento" e "Retidão Moral" (o,729, p $<0,000)$ e entre "Reconhecimento" e "Relações com os Colegas e Superiores" (0,729, p <0,000). Esse apontamento ajuda a compreender que um aumento nos escores de reconhecimento profissional deverá gerar maior nível de retidão moral e melhor relacionamento com os pares e chefias no ambiente do ensino superior, pelo menos, para essa amostra, envolvendo 17 IES brasileiras, constatação potencialmente interessante para coordenações, direções e demais instâncias acadêmicas superiores. Por fim, apresenta alguns depoimentos dos próprios docentes sobre o trabalho em suas respectivas IES. Esses depoimentos trazem contribuições que podem ser usadas em uma análise qualitativa para balizar estratégias de melhoria do trabalho em si e das condições de trabalho.

O sexto capítulo expõe as considerações finais sobre QVT docente, com um breve resumo sobre os principais achados da pesquisa e contribuições para a Administração Pública. O leitor observará contemplações sobre o comportamento complexo dos fatores e indicadores de QVT, que são determinantes para um comportamento laboral saudável. E gostará de ter respostas para as seguintes questões relevantes: (i) Qual a relação existente entre sentido do trabalho, estresse e sofrimento psicológico?; (ii) Docentes dos gêneros masculino e feminino são sensíveis a quais indicadores de QVT?; (iii) Que estratégias defensivas são utilizadas pelos docentes para terem experiências mais positivas no ambiente de trabalho e aumentarem as suas percepções de QVT? 
Esse livro me inspirou a compreender que buscar e implantar QVT envolve planejamento, avaliação, uso de estratégias individuais e coletivas no ambiente de trabalho, assim como retrata a identificação de fatores potencializadores ou inibidores de tarefas, aprendizado com experiências anteriores, promoção de ambientes saudáveis e seguros. Todos esses esforços

\section{REFERÊNCIAS}

Calvosa, M. (2010). Tecnologia e organização do trabalho. Rio de Janeiro, RJ: Fundação Cecierj.

Morin, E. M. (2001). Os sentidos do trabalho. RAE-Revista de Administração de Empresas, 41(3), 8-19. doi: 10.1590/Soo3475902001000300002

Morin, E. M. (2011). Healthy workplaces and leadership. RAE-Revista de Administração de Empresas, 51(3), 310-310. doi: 10.1590/So03475902011000300010

Rodrigues, A. L., Barrichello, A., \& Morin, E. M. (2016). Os sentidos do trabalho para profissionais de enfermagem: Um estudo multimétodos. RAE-Revista de Administração de Empresas, 56(2), 192-208. doi: 10.1590/So034-759020160206 privilegiam, de modo contemplativo, a saúde do colaborador, evitando causas para doenças e sofrimentos, promovendo satisfação, contentamento e o devido equilíbrio vida-trabalho. $\mathrm{O}$ estudo e a análise da QVT têm se mostrado componentes fundamentais em favor das organizações, permitindo gerar propósitos na vida laboral dos seus colaboradores.
Vilas Boas, A. A., Pires, A. A., Faria, D. A, \& Morin, E. M. (2018). Fatores de qualidade de vida no trabalho dos docentes de instituições federais de ensino superior das Regiões Sudeste, Centro-Oeste e Distrito Federal. Brazilian Journal of Development, 4, 2458-2482. doi: 10.36229/978-65-5866-034-7.cap.06

Vilas Boas, A. A., Morin, \& E. M. (2016). Sentido do trabalho e fatores de qualidade de vida no trabalho: A percepção de professores brasileiros e canadenses. Revista Alcance (Online), 23, 272-292. doi: 10.14210/alcance.v23n3(Jul-Set).p272-292

Vilas Boas, A. A., \& Morin, E. M. (2017). Qualidade de vida no trabalho: Um modelo sistêmico de análise. Revista Administração em Diálogo$R A D, 19,62-90$. doi: 10.20946/rad.v19i2.31720

Vilas Boas, A. A., \& Morin, E. M. (2021). Qualidade de vida no trabalho: Um modelo sistêmico. Minas Gerais: Editora UFLA.

\section{CONTRIBUIÇÃO DE AUTORIA}

Marcello Vinicius Doria Calvosa trabalhou na conceitualização e abordagem teórica-metodológica, na revisão teórica e redação e revisão final do manuscrito. 